\title{
BMJ
}

\section{Poverty and blindness in Pakistan: results from the Pakistan national blindness and visual impairment survey}

\author{
Clare E Gilbert, reader in international eye health, ${ }^{1}$ S P Shah, research fellow in ophthalmology, ${ }^{1}$ \\ M Z Jadoon, consultant epidemiologist, ${ }^{2} \mathrm{R}$ Bourne, consultant ophthalmologist, ${ }^{3} \mathrm{~B}$ Dineen, research \\ fellow in epidemiology, ${ }^{1}$ M A Khan, executive director, ${ }^{2} \mathrm{G}$ J Johnson, professor in ophthalmology, \\ M D Khan, professor in ophthalmology, ${ }^{2}$ on behalf of the Pakistan National Eye Survey Study Group
}

\section{ABSTRACT}

Health, London School of Hygiene and Tropical Medicine, London WC1E 7HT

${ }^{2}$ Pakistan Institute of Community Ophthalmology, Peshawar,

Pakistan

${ }^{3}$ Ophthalmology Department, Hinchingbrooke Hospital, Huntingdon, Cambridge

Correspondence to: CE Gilbert clare.gilbert@lshtm.ac.uk

doi:10.1136/bmj.39395.500046.AE
Objective To explore the association between blindness and deprivation in a nationally representative sample of adults in Pakistan.

Design Cross sectional population based survey.

Setting 221 rural and urban clusters selected randomly throughout Pakistan.

Participants Nationally representative sample of 16507 adults aged 30 or above (95.3\% response rate).

Main outcome measures Associations between visual impairment and poverty assessed by a cluster level deprivation index and a household level poverty indicator; prevalence and causes of blindness; measures of the rate of uptake and quality of eye care services.

Results 561 blind participants ( $\$ 3 / 60$ in the better eye) were identified during the survey. Clusters in urban Sindh province were the most affluent, whereas rural areas in Balochistan were the poorest. The prevalence of blindness in adults living in affluent clusters was $2.2 \%$, compared with $3.7 \%$ in medium clusters and $3.9 \%$ in poor clusters ( $\mathrm{P}<0.001$ for affluent $v$ poor). The highest prevalence of blindness was found in rural Balochistan (5.2\%). The prevalence of total blindness (bilateral no light perception) was more than three times higher in poor clusters than in affluent clusters $(0.24 \% \vee 0.07 \%$, $\mathrm{P}<0.001)$. The prevalences of blindness caused by cataract, glaucoma, and corneal opacity were lower in affluent clusters and households. Reflecting access to eye care services, cataract surgical coverage was higher in affluent clusters (80.6\%) than in medium (76.8\%) and poor areas (75.1\%). Intraocular lens implantation rates were significantly lower in participants from poorer households. $10.2 \%$ of adults living in affluent clusters presented to the examination station wearing spectacles, compared with $6.7 \%$ in medium clusters and $4.4 \%$ in poor cluster areas. Spectacle coverage in affluent areas was more than double that in poor clusters $(23.5 \% \mathrm{v} 11.1 \%$, P<0.001).

Conclusion Blindness is associated with poverty in Pakistan; lower access to eye care services was one contributory factor. To reduce blindness, strategies targeting poor people will be needed. These interventions may have an impact on deprivation in Pakistan.

\section{INTRODUCTION}

Poverty has multiple dimensions at the individual, household, and community level, in relation to material aspects (such as employment, income, costs, debt, land, consumption, and housing), services (such as education, health care, and poverty alleviation or development assistance), and social or psychological elements (such as social contact, marriage, self esteem and stigma, violence, and voice and authority). ${ }^{1}$ Poverty can, therefore, be thought of as the deprivation of opportunities that enhance human capabilities, so denying people a life of dignity, respect, and value.

Disability is often reported as a characteristic of poor people ${ }^{2}$; studies suggest that up to $15-20 \%$ of poor people in developing countries are affected. ${ }^{3}$ The detrimental impact of visual disability on life expectancy and quality of life is well documented, ${ }^{45}$ and blindness (classified in terms of the person trade-off protocol) is categorised in the sixth of seven categories of increasing disability. ${ }^{6}$ Clear evidence shows that some blinding eye diseases are a direct consequence of poverty (for example, trachoma), ${ }^{7}$ whereas blindness can lead to financial insecurity and social isolation even in affluent countries. ${ }^{8}$ Indeed, recent publications suggest that loss of economic productivity as a result of visual impairment is $\$ 8 \mathrm{bn}$ ( $£ 3.9 \mathrm{bn}$; $€ 5.5 \mathrm{bn}$ ) a year in the United States, ${ }^{9}$ and the global annual loss in gross domestic product from blindness and low vision in 2000 was estimated at between $\$ 19223 \mathrm{~m}$ and $\$ 22764 \mathrm{~m} .{ }^{10}$ Poverty and blindness are, therefore, inter-related.

The prevalence of blindness is three to four times higher in low income countries than in industrialised countries, ${ }^{11}$ and more than $75 \%$ of global blindness is either preventable or treatable. ${ }^{12}$ Information is lacking on how poverty influences the prevalence and cause of blindness in low income countries, however, despite the fact that the World Bank highlighted the lack of research into poverty and disability in the developing world. ${ }^{3}$ The aim of this study, using data collected between 2001 and 2004 during the national survey of blindness and visual impairment, ${ }^{13}$ was to explore the association between blindness, access to eye care 
services, and poverty in Pakistan, a low income country with the sixth largest population in the world. ${ }^{14}$

\section{METHODS}

A detailed description of the sampling and enumeration methods, ocular examination procedures, methods used in training, and the results of a pilot study have already been published. ${ }^{15}$

\section{Sampling strategy and sample size}

We used multistage, stratified, cluster random sampling, with probability proportional to size procedures to select a nationally representative sample of adults aged 30 years or over. On the basis of an assumed prevalence of blindness of $1.8 \%$, a random sampling error precision of $0.3 \%$, a design effect of 2.0 , and a $10 \%$ increase for potential non-response, we calculated the sample size at 16600 adults. We selected a total of 221 clusters in rural and urban sites around the country. Before the examination, we used the random walk technique to enumerate all adults who were living in households until we reached the target number. We than asked all eligible people to attend the examination station set up in their community in the following days. Enumerated people who could not attend the examination station were examined at home whenever possible. If an enumerated person did not attend for examination, we made three visits to his or her house before marking the person as a non-responder. We did not replace non-responders.

\section{Survey process}

After each enumerated participant had given verbal, informed consent, a trained interviewer took a medical history. All participants had their height and weight measured and had their distance visual acuity measured. We measured visual acuity unaided and then with distance correction, if usually worn (that is, presenting visual acuity). All participants then had non-cycloplegic automated refraction followed by an ophthalmic examination by an ophthalmologist. People with a presenting visual acuity of $<6 / 12$ in one or both eyes then had a more detailed examination, which included re-testing visual acuity with refraction results ("best" correction) and a dilated slit lamp examination. The survey team also provided treatment free of cost to participants with minor ailments (such as conjunctivitis) and referred others who needed more treatment to the nearest eye facility.

\section{Definitions used in this analysis}

We measured poverty at two levels - at cluster level and household level.

Deprivation index score - A deprivation index score at district level, stratified by urban/rural location, came from the Population and Housing Census data for 1998. This index uses the same criteria as the United Nations Development Program for deriving the human poverty index (that is, education, housing quality and congestion, residential services, and employment) and uses a scale from 0 (low deprivation) to 100 (very high deprivation). ${ }^{16}$ We categorised the degree of deprivation for each survey cluster into low (below 25th centile, index score $<45$ ), medium (25th75 th centile, index score $\geq 45$ to $<70$ ), and high deprivation (above 75 th centile, index score $\geq 70$ ). We will use the terms "affluent," "medium," and "poor" clusters, for ease of interpretation.

Household poverty - We created a novel household poverty variable by using a combination of occupation and literacy of people living in the house. We grouped people's occupations into three categories: non-manual (professional, managerial and technical, or skilled non-manual), manual (skilled manual, partly skilled manual, or unskilled manual), and other (retired, unemployed, or student). We determined household occupation by the highest status occupation within the household. For example, if only one worker lived in a household and he was a non-manual worker, this was the status for that house. If two or more working people lived in the household, we classified the house by the highest status occupation (non-manual $>$ manual $>$ other). We determined literacy for individual participants by their ability to read, write, or both. A literate household was one that contained at least one literate household member. Combining household occupation and household literacy gave three categories for household poverty: non-manual and literate ("affluent households") > non-manual and illiterate plus manual and literate ("medium households") $>$ manual and illiterate ("poor households"). We excluded participants who lived in households with the occupation status of retired/unemployed/student, whether they were literate or illiterate.

Blindness - We used the World Health Organization's categories of visual impairment, ${ }^{17}$ in which blindness is defined as a presenting visual acuity (that is, with glasses for distance if normally worn, or unaided) of less than $3 / 60$ in the better eye. People classified as totally blind (no perception of light in both eyes) were included in this group. As we assessed visual fields in only a subset of the sample, we did not include constricted visual fields in the definition.

Cause of blindness - We determined causes of visual loss according to WHO criteria. We selected a main cause for each eye, followed by selection of the main cause for the person. We based the selection of main cause for the person on the WHO recommendation that the cause selected should be the one "most amenable to treatment or prevention. ${ }^{18}$

Calculation of coverage (cataract surgery and spectacles) - Cataract surgical coverage is a measure of the uptake of services for cataract surgery. It assesses the proportion of people with operable cataract who have had surgery. We calculated cataract surgical 
coverage by using the formula $((x+y) /(x+y+z)) \times 100$, where $\mathrm{x}=$ people with unilateral pseudo/aphakia and blindness $(<3 / 60)$ in the contralateral eye; $y=$ people with bilateral pseudo/aphakia, regardless of acuity; and $\mathrm{z}=$ people with $<3 / 60$ in whom the principal cause was cataract (unilateral or bilateral).

We determined wearing of spectacles for distance vision when participants attended the clinical examination station. "Spectacle coverage" similarly evaluates the uptake of refractive error services. The "met need" were people who owned and were wearing their spectacles, whose uncorrected visual acuity was $<6 / 12$ in the better eye but whose visual acuity improved to $6 / 12$ or more wearing their own distance correction. "Unmet need" were adults who did not own spectacles or who owned spectacles of an incorrect prescription and who were $<6 / 12$ in the better eye but improved to $>6 / 12$ with "best" correction. We calculated percentage spectacle coverage as ((met need)/ $($ met need $)+($ unmet need $)) \times 100$.

Intraocular lens implantation rate-As a measure of the quality of cataract surgery, we analysed participants who had had cataract surgery after 1998 in order to determine whether they had an intraocular lens implanted at the time of surgery. We chose one eye at random for patients who had had bilateral cataract extraction within this period.

Quality of life assessment - We administered a questionnaire on quality of life and visual function in the local language to selected participants, including those who were blind. This questionnaire was developed for assessing the impact of blindness due to cataract in India. ${ }^{19}$

\section{Data analysis}

We double entered data and analysed them in Stata (release 9.0). We calculated body mass index (weight $(\mathrm{kg}) /$ height $\left.(\mathrm{m})^{2}\right)$ and classified it according to the WHO criteria $(<18.50=$ underweight, $\geq 18.5$ $<25.0=$ normal, $\geq 25.0-<30.0=$ overweight, $\geq 30.0=$ obese). ${ }^{20} \mathrm{We}$ used $\chi^{2}$ trend statistics to investigate associations. We used univariable and multivariable logistic regression with generalised estimating equations (to account for the clustered sampling) to estimate the effect of poverty on blindness. We built adjusted models by first identifying significant explanatory variables in univariable analyses and then adding them in a forward stepwise manner, starting with an empty model and adding the most significant variable first (age). The significance level for removal from the model was $\mathrm{P}=0.2$. Explanatory variables included age (linear), body mass index (linear), sex, hypertension (we defined participants as having hypertension from their medical history or if their systolic blood pressure was $>140 \mathrm{~mm} \mathrm{Hg}$, their diastolic blood pressure was $>90 \mathrm{~mm} \mathrm{Hg}$, or both) (binary), smoking status (we classified participants as smokers if they were regular current or regular past smokers of cigarettes or hookahs

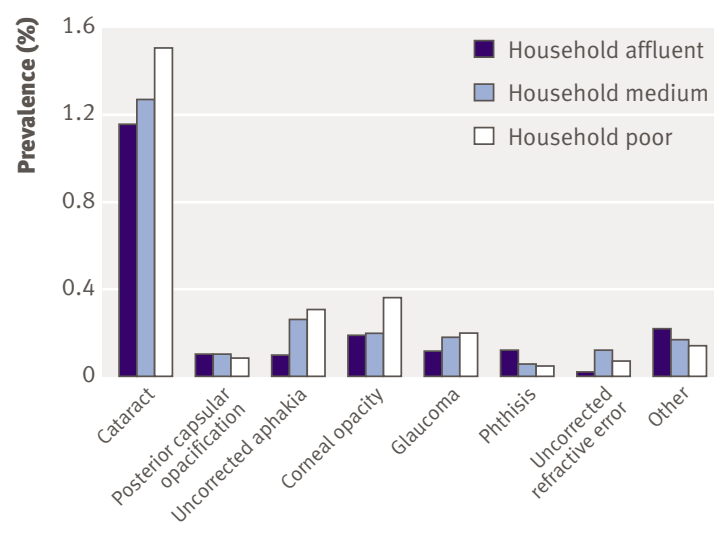

Cause specific prevalence of blindness at household level

or as non-smokers) (binary), and rural/urban dwelling (binary). As both poverty indicators include educational status/literacy and employment/occupation, we did not include these as explanatory variables. We included in the household poverty model those explanatory variables that were significant in the multivariable deprivation index model.

\section{RESULTS}

In all, 16507 participants were examined (95.3\% response rate) in 221 clusters in 94 of Pakistan's 106 districts. Data on the overall prevalence and causes of blindness have been published elsewhere. ${ }^{1321}$

In determining household poverty status, we excluded 2659 participants who were categorised as living in a household with retired/student/unemployed status. Data were missing for a further three participants. Only $19.2 \%$ of participants in affluent clusters were living in poor households, compared with $39.7 \%$ of participants in poor clusters; $31.5 \%$ of participants lived in affluent households in affluent clusters, and $32.5 \%$ lived in poor households in poor clusters. Participants living in urban clusters in Sindh province were the most affluent, whereas clusters in rural areas in Balochistan were the poorest. All poor clusters were located in rural areas.

\section{Poverty and prevalence of blindness}

The survey identified 561 blind participants; the highest prevalence of blindness was in rural Balochistan $(5.2 \%$, 95\% confidence interval $3.5 \%$ to $7.1 \%)$. Table 1 shows the prevalence of blindness at cluster and household levels, by level of poverty.

The prevalence of blindness was higher in poor clusters than in affluent clusters among participants below the age of 50 years - $1.1 \%(0.7 \%$ to $1.6 \%)$ in poor clusters, $0.8 \%(0.5 \%$ to $1.1 \%)$ in medium clusters, $0.4 \%$ $(0.2 \%$ to $0.8 \%)$ in affluent clusters; $\mathrm{P}$ for trend $=0.037$ as well as among those aged 50 years and above $-7.9 \%$ (6.7\% to $9.3 \%), 7.3 \%$ (6.5\% to $8.2 \%), 5.3 \%$ (4.2\% to $6.6 \%) ; \mathrm{P}$ for trend $=0.009$. The prevalence of total blindness (bilateral no light perception) was more than three times higher in poor clusters than in affluent 
Table1 | Prevalence of blindness and uptake of eye care services, by level of poverty in clusters and households. Values are percentages ( $95 \%$ confidence intervals)

Prevalence/uptake

Blindness

Cluster:

\begin{tabular}{ll}
\hline Affluent & $2.2(1.8$ to 2.7$)$ \\
\hline Medium & $3.7(3.3$ to 4.1$)$ \\
\hline Poor & $3.9(3.4$ to 4.6$)$ \\
\hline Household: & \\
\hline Affluent & $2.2(1.8$ to 2.7$)$ \\
\hline Medium & $2.5(2.1$ to 3.0$)$ \\
\hline Poor & $4.7(4.1$ to 5.3$)$ \\
\hline
\end{tabular}

Cataract surgical coverage

Cluster:

\begin{tabular}{ll}
\hline Affluent & $80.6(75.1$ to 85.5$)$ \\
\hline Medium & $76.8(73.4$ to 79.9$)$ \\
\hline Poor & $75.1(69.9$ to 79.9$)$ \\
\hline Household: & $80.0(74.2$ to 84.9$)$ \\
\hline Affluent & $80.4(75.6$ to 84.7$)$ \\
\hline Medium & $71.4(66.7$ to 75.8$)$ \\
\hline
\end{tabular}

Intraocular lens implantation rates

Cluster:

\begin{tabular}{ll}
\hline Affluent & $66.4(57.4$ to 74.6$)$ \\
\hline Medium & $46.2(40.9$ to 51.5$)$ \\
\hline Poor & $61.3(53.4$ to 68.9$)$ \\
\hline Household: & $68.4(60.4$ to 75.7$)$ \\
\hline Affluent & $55.5(47.3$ to 63.5$)$ \\
\hline Medium & $45.3(38.3$ to 52.4$)$ \\
\hline
\end{tabular}

Spectacle coverage

Cluster:

\begin{tabular}{lc}
\hline Affluent & $23.5(20.1$ to 27.2$)$ \\
\hline Medium & $11.9(9.8$ to 14.1$)$ \\
\hline Poor & $11.1(8.2$ to 14.4$)$ \\
\hline Household: & $25.9(22.1$ to 30.1$)$ \\
\hline Affluent & $14.9(12.1$ to 18.2$)$ \\
\hline Medium & $7.3(5.2$ to 10.0$)$ \\
\hline
\end{tabular}

clusters $(0.24 \%$ versus $0.07 \%$; $\mathrm{P}<0.001)$. We found similar patterns at household level.

\section{Poverty and causes of blindness}

Cataract was the leading cause of blindness $(\mathrm{n}=289$, $51.5 \%$ ). The figure shows the cause specific prevalence of blindness for the different poverty levels in households. In adults with vision $<6 / 18$ to $\geq 6 / 60$ (better eye), cataract was the leading cause in poor clusters $(\mathrm{n}=235$, $47.0 \%)$ and medium clusters $(\mathrm{n}=478,45.7 \%)$, whereas uncorrected refractive error was the leading cause in affluent clusters $(\mathrm{n}=259,46.5 \%)$, followed by cataract $(\mathrm{n}=170,36.0 \%)$.

\section{Poverty and access to eye care services}

Table 1 shows the differences in cataract surgical coverage, intraocular lens implantation rates, and spectacle coverage. We identified sex differences in cataract surgical coverage at household level; coverage was higher in men than in women at all levels of poverty. In affluent clusters, $10.2 \%$ of adults presented wearing spectacles, compared with $6.7 \%$ in medium clusters and $4.4 \%$ in poor clusters $(\mathrm{P}<0.001$ for affluent $v$ poor). Six hundred and forty five people ( 850 eyes) had been operated on within three years of the survey and were included in the analysis of implantation rates. Three hundred and fifty eight (53.9\%) adults had an intraocular lens implanted at the time of their cataract surgery; rates were higher among affluent participants. Spectacle coverage in affluent clusters was more than double that in medium and poor clusters $(\mathrm{P}<0.001$ for affluent $v$ poor), and women living in poor households had the lowest coverage $(6.2 \%)$.

\section{Quality of life}

We administered quality of life questionnaires to 72 (of 94 eligible) blind participants living in affluent households, to 98 (of 128 eligible) living in medium households, and to 167 (of 214 eligible) living in poor households. The total score distribution was negatively skewed. We found no association between household poverty status and quality of life scores; median scores were 58 (affluent), 65 (medium), and 61 (poor) (Kruskal Wallis $\mathrm{P}=0.63$ ).

\section{Association analysis}

We identified demographic differences between affluent, medium, and poor clusters and households. Adults in poor clusters were more likely to be older $(\mathrm{P}<0.001)$ (probably reflecting the urban migration of the young), to have a lower body mass index $(\mathrm{P}<0.001)$, and to be male $(\mathrm{P}<0.001)$. Poor clusters were more likely to be located in rural areas $(\mathrm{P}<0.001)$. The prevalence of blindness was significantly higher among elderly people (mean age among blind participants 65 . 4 years versus 46.7 years in others; $\mathrm{P}<0.001$ ), those with low body mass index (mean 20.4 in blind participants versus 22.8 in others; $\mathrm{P}<0.001$ ), those living in rural areas $(3.8 \%$ versus $2.5 \% ; \mathrm{P}<0.001)$, and in women (after adjustment for age differences). Nonsmokers were also more likely to be blind, but this association was confounded by sex differences in smoking habits in Pakistan. Table 2 provides the point estimates and 95\% confidence intervals for the univariable and adjusted models for the risk of blindness. We found no significant differences between the affluent and medium clusters $(\mathrm{P}=0.25)$ and households $(\mathrm{P}=0.55)$.

\section{DISCUSSION}

The prevalence of blindness was significantly higher in poor clusters and in poor households in this study. The prevalence of blinding cataract was lower among affluent participants, which may partly be explained by the finding that poor participants had lower rates of cataract surgery and so remained blind. Poor households were also more likely to have had less than 
optimal cataract surgery (that is, without intraocular lens implantation); this was also reflected in the higher prevalence of blindness due to uncorrected aphakia. Spectacle coverage was low overall and was particularly low in poor households and clusters and in women. The finding of a higher prevalence of blindness due to glaucoma among poor people is not surprising, as preventing blindness from glaucoma requires early presentation and diagnosis followed by either surgery or long term topical drugs, all of which incur direct and indirect costs. The prevalence of corneal blindness was also higher among poor participants, which is also not surprising, given that trachoma is still endemic in Pakistan ${ }^{22}$ and keratitis after superficial trauma is common in agricultural workers.

To our knowledge, this is the first study to investigate associations between blindness, service delivery/quality, and composite measures of poverty at both micro and macro levels. Strengths of our study include the large sample size, which together with a rigid sampling strategy and low non-response rates provided a nationally representative sample of the adult population. The sample was, therefore, likely to represent the economic range of households in Pakistan. A limitation of the study is that we did not collect information on monthly income and expenditure or on household assets and household size, as associations with poverty

\begin{tabular}{|c|c|c|c|c|}
\hline & \multicolumn{2}{|c|}{ Univariable } & \multicolumn{2}{|c|}{ Multivariable } \\
\hline & Odds ratio $(95 \% \mathrm{Cl})$ & $P$ value & Odds ratio $(95 \% \mathrm{Cl})$ & $P$ value \\
\hline \multicolumn{5}{|c|}{ Levels of poverty } \\
\hline \multicolumn{5}{|l|}{ Cluster: } \\
\hline Affluent & 1 & & 1 & \\
\hline Medium & $1.69(1.33$ to 2.15$)$ & $<0.001$ & 1.18 (0.88 to 1.58$)$ & 0.253 \\
\hline Poor & 1.81 (1.39 to 2.35$)$ & $<0.001$ & 1.43 (1.08 to 2.02$)$ & 0.03 \\
\hline \multicolumn{5}{|l|}{ Household: } \\
\hline Affluent & 1 & & 1 & \\
\hline Medium & 1.12 (0.86 to 1.47$)$ & 0.88 & 0.91 (0.67 to 1.30$)$ & 0.549 \\
\hline Poor & 2.14 (1.67 to 2.73$)$ & $<0.001$ & 1.53 (1.17 to 2.01$)$ & 0.002 \\
\hline \multicolumn{5}{|l|}{ Other variables } \\
\hline 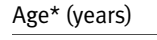 & 1.08 (1.07 to 1.09$)$ & $<0.001$ & 1.08 (1.07 to 1.09$)$ & $<0.001$ \\
\hline BMl† $\left(\mathrm{kg} / \mathrm{m}^{2}\right)$ & 0.89 (0.87 to 0.91$)$ & $<0.001$ & 0.93 (0.89 to 0.97$)$ & 0.002 \\
\hline \multicolumn{5}{|l|}{ Sex: } \\
\hline Female & 1 & & 1 & \\
\hline Male & $0.97(0.82$ to 1.14$)$ & 0.725 & $0.66(0.45$ to 0.96$)$ & 0.033 \\
\hline \multicolumn{5}{|l|}{ Dwelling: } \\
\hline Urban & 1 & & \multirow{2}{*}{ Dropped } & \\
\hline Rural & 1.55 (1.27 to 1.88$)$ & $<0.001$ & & \\
\hline \multicolumn{5}{|l|}{ Smoker: } \\
\hline Yes & 1 & & \multirow{2}{*}{ Dropped $\ddagger$} & \\
\hline No & 1.47 (1.1 to 1.95$)$ & 0.007 & & \\
\hline
\end{tabular}

Hypertensive:

$\begin{array}{lcc}\text { Yes } & 1 & \\ \text { No } & 0.93(0.62 \text { to } 1.39) & 0.3\end{array}$ Dropped

$\star 8 \%$ increase in odds of blindness for each year increase in age.

$\lceil 7 \%$ decrease in odds of blindness for each unit increase in body mass index (BMI).

$\ddagger$ Smoking confounded by sex. were not a primary outcome of the survey. At household level, we used occupation combined with literacy as a measure of poverty, which, although it allows women to be categorised as well as men, may not capture many of the complex aspects of poverty. At cluster level, we used a district level indicator, which, although stratified on rural or urban location, may not apply evenly across districts. However, studies in the UK have used postcode level derived indices of poverty to investigate deprivation and visual impairment. ${ }^{2224}$ As with all studies in which data are not at the individual level, the findings are subject to the ecological fallacy, which is likely to be more pronounced at cluster level than at household level. The dynamic processes and temporal associations underlying the blindness-poverty cycle are better explored in longitudinal studies, so caution is needed when interpreting results from this cross sectional study.

One explanation for our findings is that a significantly higher incidence of blinding eye diseases exists among poor people. However, differences in the uptake of eye care services suggest that inequity of access is an important contributory factor. Lower uptake, particularly for refractive error, suggests that services are not available in poorer areas or that considerable barriers to access exist. In Pakistan, a common cause of visual impairment (but not of blindness) is uncorrected refractive error, ${ }^{21}$ which has a highly cost effective and easily applied intervention. Refraction and optical services need to be expanded in Pakistan, to ensure that they are accessible to all sectors of the adult population. In this survey, as in many other studies in developing countries, cost was cited as an important barrier to cataract surgery, ${ }^{25}$ even though many eye care providers offer free or subsided surgery. The presence of blindness due to cataract among affluent participants also indicates that other barriers exist that need to be elucidated and overcome (such as fear of treatment).

Research exploring associations between poverty and blindness in populations is limited, but studies in the United States and India have shown associations between reduced income and visual impairment. ${ }^{2627}$ Other studies have used employment status, literacy, or both, showing that illiteracy and lower class of employment were associated with higher rates of visual impairment, lower cataract surgical coverage, poorer outcomes after cataract surgery, and lower spectacle coverage. $^{28-32}$

Globally, cataract is responsible for almost half of all blindness, ${ }^{11}$ and cataract surgery is one of the most common elective surgical procedures. Indeed, WHO estimates that if $95 \%$ of people with operable cataract had surgery this would avert more than 3.5 million disability adjusted life years (DALYs) a year globally. ${ }^{33}$ Data from the survey in Pakistan indicate that approximately 900000 people still have operable cataract despite a greatly expanded national eye care programme, but evidence from this study shows that cataract services are accessible to poor people, which is highly commendable. ${ }^{21}$ The economic case for cataract 


\section{WHAT IS ALREADY KNOWN ON THIS TOPIC}

Blindness and visual impairment are more common in developing countries than in industrialised countries, but information on associations with poverty is limited

Cataract is the most common cause of blindness in Pakistan, and cataract surgery is a highly cost effective intervention

\section{WHAT THIS STUDY ADDS}

Poverty, measured at household and cluster levels with composite indices, was significantly associated with blindness in Pakistan

Lower uptake of eye care services and poorer quality services contribute to the higher rates of blindness among poor people
Unit, 2006 (available at www.vision2020uk.org.uk/library.asp? section $=000100050005$ ).

2 Narayan D, Patel R, Schafft K, Rademacher A, Koch-Schulte S. Voices of the poor: can anyone hear us? New York: World Bank, Oxford University Press, 2000.

3 Elwan A. Poverty and disability: a survey of the literature. Washington DC: World Bank,

1999. (Social protection discussion paper No. 9932.)

4 McCarty CA, Nanjan MB, Taylor HR. Vision impairment predicts 5 year mortality. Br J Ophthalmol 2001;85:322-6.

5 Vu HT, Keeffe JE, McCarty CA, Taylor HR. Impact of unilateral and bilateral vision loss on quality of life. Br J Ophthalmol 2005;89:360-3.

6 Murray CJ, Lopez AD. Regional patterns of disability-free life expectancy and disability-adjusted life expectancy: global burden of disease study. Lancet 1997;349:1347-52.

7 Whitcher JP, Srinivasan M, Upadhyay MP. Corneal blindness: a global perspective. Bull World Health Organ 2001;79:214-21.

8 Vale D. Unseen: neglect, isolation and household poverty amongst older people with sight loss . London: Royal National Institute for the Blind, 2004.

surgery is strong: cataract surgery is one of the most cost effective of all interventions ( $\$ 100$ per DALY averted), ${ }^{34}$ and an economic evaluation of the eye care programme in Gambia between 1986 and 1997 showed an internal rate of return of $10 \% .{ }^{35}$ In addition, after cataract surgery people can become economically productive again. ${ }^{36}$ In countries of limited resources, evidence of cost effectiveness and economic benefit can be used by policy makers for prioritisation and for advocacy to mobilise additional resources. The challenges are to ensure that poor people, particularly women, have the potential to benefit. This is particularly relevant in Pakistan, where the proportion of the population living below the poverty line doubled between 1987 and $2003 .^{37}$

We are grateful for the contribution of the Pakistan National Eye Survey Study Group, which consisted of Shad Mohammed, Zia Uddin Sheik, Asad Aslam, Nasim Panazai, Shabbir Mir Niaz Ali, Pak Sang Lee (technical coordinator, International Centre for Eye Health, London), Ikram Ullah Khan (biomedical engineer, Pakistan Institute of Community Ophthalmology), Haroon Awan (Sightsavers International), Rubina Gillan (Fred Hollows Foundation), Babar Qureshi (Christoffel Blindenmission), Mohammed Shabbir and Falak Naz (clinical and community ophthalmologists, North West Frontier Province Team), Abdul Ghafoo and Kiramatullah (survey ophthalmologists, Punjab and Baluchistan Teams), Waheed Shaikh and Amjad Shaikh (survey ophthalmologists, Sindh Team). We also thank Tauqeer Abbas and Fakhre-e Alam for data entry; Mahwash Akhtar-Khan, Yelena Alexander, and Rahul Shah for assisting in data cleaning; and Fazl-Subhan and Jyoti Shah for assisting with financial management. Heidelberg Engineering (Heidelberg, Germany) kindly lent two HRT-II instruments. Lateef Brothers and S Haj Ameerdin and Sons, both based in Lahore, Pakistan, were generous in their instrument support. The NWFP divisions of the companies Remington and Kobec Ophthalmic generously donated drugs. Contributors: CEG had the idea for the paper and the analyses and wrote the first draft. SPS did all the analyses and contributed to writing the firs draft. MZJ contributed to the design of the survey and was responsible for managing the field teams in Pakistan. RB was responsible for clinical training and quality control during the survey. BD contributed to the design of the survey and had overall responsibility for setting up and overseeing the survey. MAK assisted in clinical training and managing the logistics in Pakistan. GJJ had overall responsibility for the survey in the UK. MDK initiated the survey and had overall responsibility for the survey in Pakistan. CEG is the guarantor.

Funding: Sightsavers International, Christoffel Blinden Mission, Fred Hollows Foundation, World Health Organization-Pakistan Office. Competing interests: None declared.

Ethical approval: Pakistan Medical Research Council.

Provenance and peer review: Not commissioned; externally peer reviewed.

1 Gooding K. Poverty and blindness: a survey of the literature . Haywards Heath: Sightsavers International Programme Developmen

Rein DB, Zhang P, Wirth KE, Lee PP, Hoerger TJ, McCall N, et al. The economic burden of major adult visual disorders in the United States. Arch Ophthalmol 2006;124:1754-60.

10 Frick KD, Foster A. The magnitude and cost of global blindness: an increasing problem that can be alleviated. Am I Ophthalmol 2003;135:471-6.

11 Resnikoff S, Pascolini D, Etya'ale D, Kocur I, Pararajasegaram R, Pokharel GP, et al. Global data on visual impairment in the year 2002 . Bull World Health Organ 2004;82:844-51.

12 WHO. Magnitude and causes of visual impairment. Fact sheet No 282, November 2004 (www.who.int/mediacentre/factsheets/fs282/en/ index.html).

13 Jadoon MZ, Dineen B, Bourne RR, Shah SP, Khan MA, Johnson GJ, et al. Prevalence of blindness and visual impairment in Pakistan: the Pakistan national blindness and visual impairment survey. Invest Ophthalmol Vis Sci 2006;47:4749-55

14 Government of Pakistan, Ministry of Economic Affairs, Statistics Division. Population census organization. 1998 (http://statpak.gov. $\mathrm{pk} /$ depts/pco/index.html)

15 Bourne R, Dineen B, Jadoon Z, Lee PS, Khan A, Johnson GJ, et al. The Pakistan national blindness and visual impairment survey research design, eye examination methodology and results of pilot study. Ophthalmic Epidemiol 2005;12:321-33.

16 Profile of regional inequality: Social Policy and Development Centre, annual review. Karachi, Pakistan: Oxford University Press, 2001:80-113.

17 Johnson GJ, Minassian DC, Weale R, eds. The epidemiology of eye disease . London: Chapman \& Hall Medical, 1998:8-30.

18 WHO. Coding instructions for the WHO/PBL eye examination record (version III) . Geneva: WHO, 1988.

19 Fletcher AE, Ellwein LB, Selvaraj S, Vijaykumar V, Rahmathullah R, Thulasiraj RD. Measurements of vision function and quality of life in patients with cataracts in southern India. Report of instrument development. Arch Ophthalmol 1997;115:767-74.

20 WHO. Global database on body mass index. 2005 (www.who.int/ bmi/index.jsp).

21 Dineen B, Bourne RR, Jadoon Z, Shah SP, Khan MA, Foster A, et al. Causes of blindness and visual impairment in Pakistan: the Pakistan national blindness and visual impairment survey. $\mathrm{Br} J$ Ophthalmol 2007;91:1005-10.

22 National Task Force on Trachoma. Report on trachoma rapid assessment in Pakistan . Islamabad: Ministry of Health, Government of Pakistan, 2002.

23 Fraser S, Bunce C, Wormald R, Brunner E. Deprivation and late presentation of glaucoma: case-control study. BMJ 2001;322:639-43.

24 Smith LK, Thompson JR, Woodruff G, Hiscox F. Social deprivation an age at presentation in amblyopia. J Public Health Med 1994;16:348-51.

25 Jadoon Z, Shah SP, Bourne R, Dineen B, Khan MA, Gilbert CE, et al. Cataract prevalence, cataract surgical coverage and barriers to uptake of cataract surgical services in Pakistan: the Pakistan national blindness and visual impairment survey. Br J Ophthalmol 2007;91:1269-73.

26 Tielsch JM, Sommer A, Katz J, Quigley H, Ezrine S. Socioeconomic status and visual impairment among urban Americans. Arch Ophthalmol 1991;109:637-41.

27 Dandona L, Dandona R, Srinivas M, Giridhar P, Vilas K, Prasad MN, et al. Blindness in the Indian state of Andhra Pradesh. Invest Ophthalmol Vis Sci 2001;42:908-16.

28 Murthy GV, Gupta S, Ellwein LB, Munoz SR, Bachani D, Dada VK. A population-based eye survey of older adults in a rural district of Rajasthan: I. Central vision impairment, blindness, and cataract surgery. Ophthalmology 2001;108:679-85. 
29 Dineen BP BR, Ali SM, Noorul Huq DM, Johnson GJ. Prevalence and causes of blindness and visual impairment in Bangladeshi adultsresults of the national blindness and low vision survey of Bangladesh. BrJ Ophthalmol 2003;87:820-8.

30 Nirmalan PK, Padmavathi A, Thulasiraj RD. Sex inequalities in cataract blindness burden and surgical services in south India. $\mathrm{Br}$ J Ophthalmol 2003;87:847-9.

31 Thulasiraj RD, Reddy A, Selvaraj S, Munoz SR, Ellwein LB. The Sivaganga eye survey: II. Outcomes of cataract surgery. Ophthalmic Epidemiol 2002;9:313-24.

32 Bourne RR, Dineen BP, Huq DM, Ali SM, Johnson GJ. Correction of refractive error in the adult population of Bangladesh: meeting the unmet need. Invest Ophthalmol Vis Sci 2004;45:410-7.

33 Baltussen R, Sylla M, Mariotti SP. Cost-effectiveness analysis of cataract surgery: a global and regional analysis. Bull World Health Organ 2004;82:338-45.
34 Laxminarayan R, Chow J, Shahid-Salles SA. Intervention costeffectiveness: overview of main messages. Disease control priorities in developing countries . 2nd ed. New York: Oxford University Press, 2006:35-86.

35 Frick KD, Foster A, Bah M, Faal H. Analysis of costs and benefits of the Gambian eye care program. Arch Ophthalmol 2005;123:239-43.

36 Javitt J, Venkataswamy G, Sommer A. The economic and social aspect of restoring sight. In Henkind P, ed. ACTA: 24th International Congress of Ophthalmology . New York: JP Lippincott, 1983:1308-12.

37 Hussein A. Pakistan national human development report, 2003: poverty, growth and governance . Karachi: United Nations Development Programme, 2003 (available at www.un.org.pk/nhdr/nhdr-pak-2003.pdf).

Accepted: 17 October 2007 